\title{
Prevalence of the Academic Research Consortium for High Bleeding Risk Criteria and Prognostic Value of a Simplified Definition
}

\author{
Katsuya Miura, MD; Takenobu Shimada, MD; Masanobu Ohya, MD; Ryosuke Murai, MD; \\ Hidewo Amano, MD; Shunsuke Kubo, MD; Takeshi Tada, MD, PhD; Hiroyuki Tanaka, MD; \\ Yasushi Fuku, MD; Tsuyoshi Goto, MD; Kazushige Kadota, MD, PhD
}

\begin{abstract}
Background: The Academic Research Consortium for High Bleeding Risk (ARC-HBR) criteria have been suggested as the standard definition of HBR. However, the prevalence of individual criteria and their prognostic value for long-term bleeding events after percutaneous coronary intervention are scarcely studied.

Methods and Results: The study population comprised 1,193 patients treated with everolimus-eluting stents between 2010 and 2011. Data on all 17 major and minor criteria of the ARC-HBR definition were retrospectively collected, and applied to this study population. Major bleeding was defined as the occurrence of a BARC type 3 or 5 bleeding event. A simplified definition was developed by excluding the low-frequency criterion, and the prognostic value was assessed by a receiver-operating characteristic curve. Mean follow-up was 2,996 \pm 433 days and there were $656 \mathrm{HBR}$ patients (55.0\%). The cumulative incidence of major bleeding was significantly higher in the HBR group than in the non-HBR group ( $16.2 \%$ vs. $5.7 \%$ at 8 years, $P<0.001$ ). The frequencies of 6 of the 17 criteria were less than $1 \%$. The prognostic value of the simplified definition made by excluding these 6 criteria for major bleeding was comparable to that of the original (c-statistic $=0.598$ and $0.600, P=0.08$ ).
\end{abstract}

Conclusions: Some risk criteria of the ARC-HBR definition are observed infrequently. Our simplified definition identified patients with long-term bleeding risk as successfully as the original definition.

Key Words: Bleeding; Coronary artery disease; Percutaneous coronary intervention

$\mathbf{P}$ rolonged dual antiplatelet therapy (DAPT) reduces the risk of thrombotic events, but is associated with higher risk of bleeding events. ${ }^{1-4}$ The current guidelines recommend assessment of each patient on the basis of the risk score to minimize bleeding complications in patients with high bleeding risk (HBR).$^{5-7}$ However, HBR patients are not well defined and the definition of HBR has varied among studies. ${ }^{8-12}$ Recently, the Academic Research Consortium (ARC) for HBR proposed a new definition consisting of 17 major and minor criteria to standardize HBR. Natsuaki et $\mathrm{al}^{13}$ reported the generality of the ARCHBR definition in a real-world setting. In their study, however, some data for the ARC-HBR criteria were not available and a bleeding event was defined according to the Global Utilization of Streptokinase and Tissue Plasminogen Activator for Occluded Coronary Arteries criteria. To date, the prevalence and influence of all the ARC-HBR criteria has not been fully elucidated. Therefore, we aimed to investigate the prevalence of all the risk criteria and the prognostic ability of the ARC-HBR criteria for long-term bleeding events based on the Bleeding Academic Research Consortium (BARC) after percutaneous coronary intervention (PCI). We also sought to develop a user-friendly version to easily apply the HBR definition in daily practice.

\section{Study Population}

This study was a retrospective single-center study. Between January 2010 and December 2011, 2,426 patients were underwent PCI using a drug-eluting stent, and of them a total of 1,787 consecutive patients undergoing everolimuseluting stent (EES; Xience V, Abbott Vascular, Santa Clara, CA, USA) implantation between January 2010 and December 2011 were enrolled. ${ }^{14}$ After excluding patients with repeat EES implantation $(n=288)$, combined use of EES and other types of stent $(n=280)$, and in-hospital events (in-hospital death: $n=17$, in-hospital definite stent

Received April 30, 2020; revised manuscript received May 15, 2020; accepted May 25, 2020; J-STAGE Advance Publication released online July 16, 2020 Time for primary review: 12 days

Department of Cardiology, Kurashiki Central Hospital, Kurashiki, Japan

Mailing address: Katsuya Miura, MD, Department of Cardiology, Kurashiki Central Hospital, 1-1-1 Miwa, Kurashiki 710-8602, Japan. E-mail: kmiura06@gmail.com

All rights are reserved to the Japanese Circulation Society. For permissions, please e-mail: cj@j-circ.or.jp

ISSN-1346-9843 


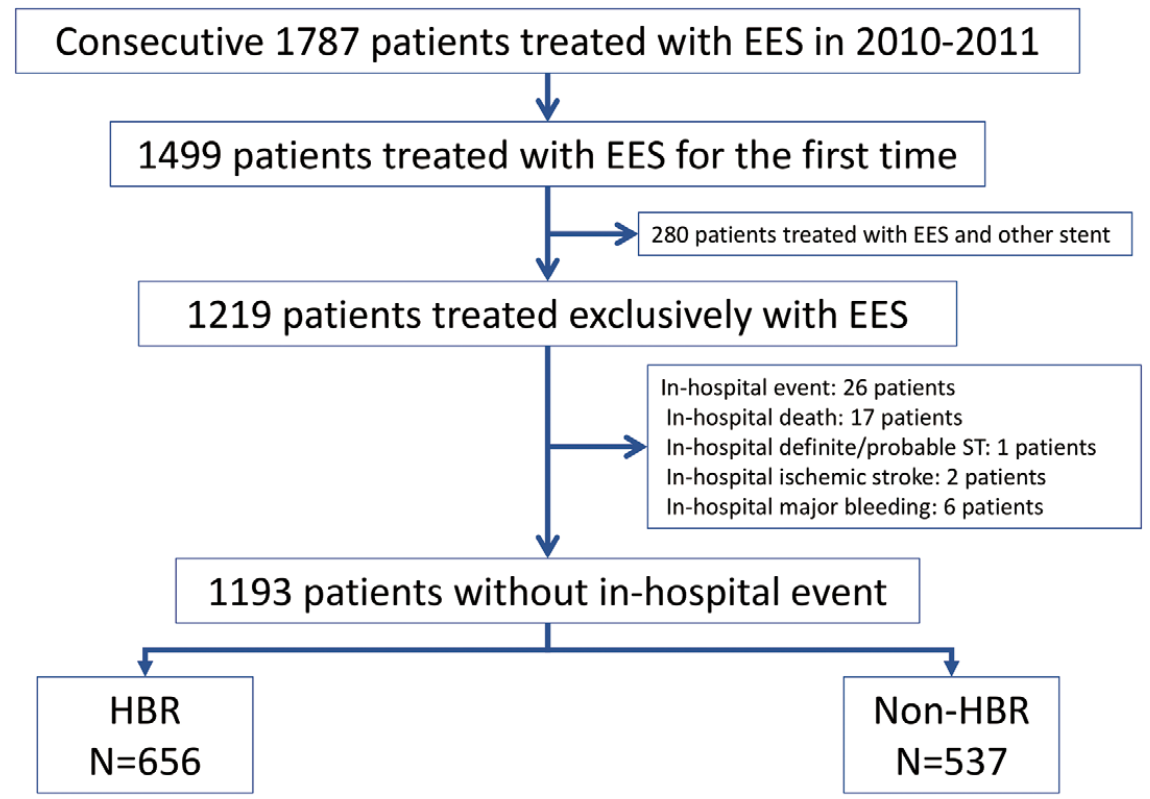

Figure 1. Flow chart of patient selection. EES, everolimus-eluting stent; HBR, high bleeding risk; ST, stent thrombosis.

thrombosis [ST]: $n=1$, in-hospital ischemic stroke: $n=2$, in-hospital major bleeding: $n=6$ ), we analyzed 1,193 patients (Figure 1). The procedures were in accordance with the Declaration of Helsinki. Informed consent was given by all patients for both the procedure and subsequent data collection and analysis for research purposes, and the study was approved by the institutional ethics committee.

\section{Study Definitions and Outcomes}

Primary bleeding endpoint was defined as a BARC type 3 or 5 bleeding event. ${ }^{15}$ Primary ischemic endpoint was defined as a composite of ST, myocardial infarction (MI) or ischemic stroke. The endpoints of this study were allcause death, cardiac death, MI, definite or probable ST, target lesion revascularization, and ischemic stroke. ST and MI were defined according to the ARC definitions. ${ }^{16}$

\section{Follow-up and Data Collection}

Serial angiographic follow-up was routinely scheduled at 8 and 20 months after PCI. Baseline data of all 17 major and minor criteria of the ARC-HBR definition and the clinical follow-up information were obtained at the time of the office visit, by telephone survey, or by mail to the primary care physician or patient. The study population was divided into 2 groups according to the ARC-HBR definition, which has been described previously (Supplementary Table 1). ${ }^{17}$

\section{Antiplatelet Therapy}

All the patients were pretreated with aspirin (100 mg daily) and ticlopidine (200 mg daily)/clopidogrel ( $75 \mathrm{mg}$ daily). DAPT for at least 8 months after the index procedure was recommended, but the duration of antiplatelet therapy was left to the discretion of each physician. The status of antiplatelet therapy was evaluated throughout the follow-up period, and persistent discontinuation of DAPT was defined as withdrawal of aspirin or thienopyridine for at least 2 office visits or telephone inquiries.

\section{Statistical Analysis}

Categorical variables were compared using the chi-square test. Continuous variables are expressed as mean \pm SD and compared using Student's t-test or the Wilcoxon rank-sum test based on the distribution. The cumulative incidence was estimated using the Kaplan-Meier method, and differences were assessed using the log-rank test. Cox proportional hazard model was used to estimate the effects of the HBR group relative to the non-HBR group for clinical events, which was expressed as hazard ratios and their $95 \%$ confidence intervals (CIs). We did not make any statistical adjustment models because the ARC-HBR definition should be considered as indicator variables for future events and summarized the relevant confounders. The cumulative incidence of the primary bleeding endpoint was assessed on the basis of the presence or absence of the individual ARC-HBR criterion, and according to the number of ARC-HBR criteria. The cumulative incidence of the primary bleeding endpoint was also assessed according to the number of ARC-HBR major and minor criteria. Patients with ARC-HBR major criteria were included in the $\geq 2$ majors, or 1 major group according to the number of major criteria regardless of the number of overlapping minor criteria. Patients with $\geq 2$ ARC-HBR minor criteria without major criteria were included in the $\geq 2$ minors without major group. A simplified definition was generated from the ARC-HBR definition by excluding the criteria with frequencies $<1 \%$. The discrimination performance of the original and simplified definitions was assessed by calculating the area under the receiver-operating characteristic curve and expressed as the c-statistic. All P-values $<0.05$ were considered to be significant. Statistical analyses were performed using JMP 9.0 (SAS Institute, Cary, NC, 

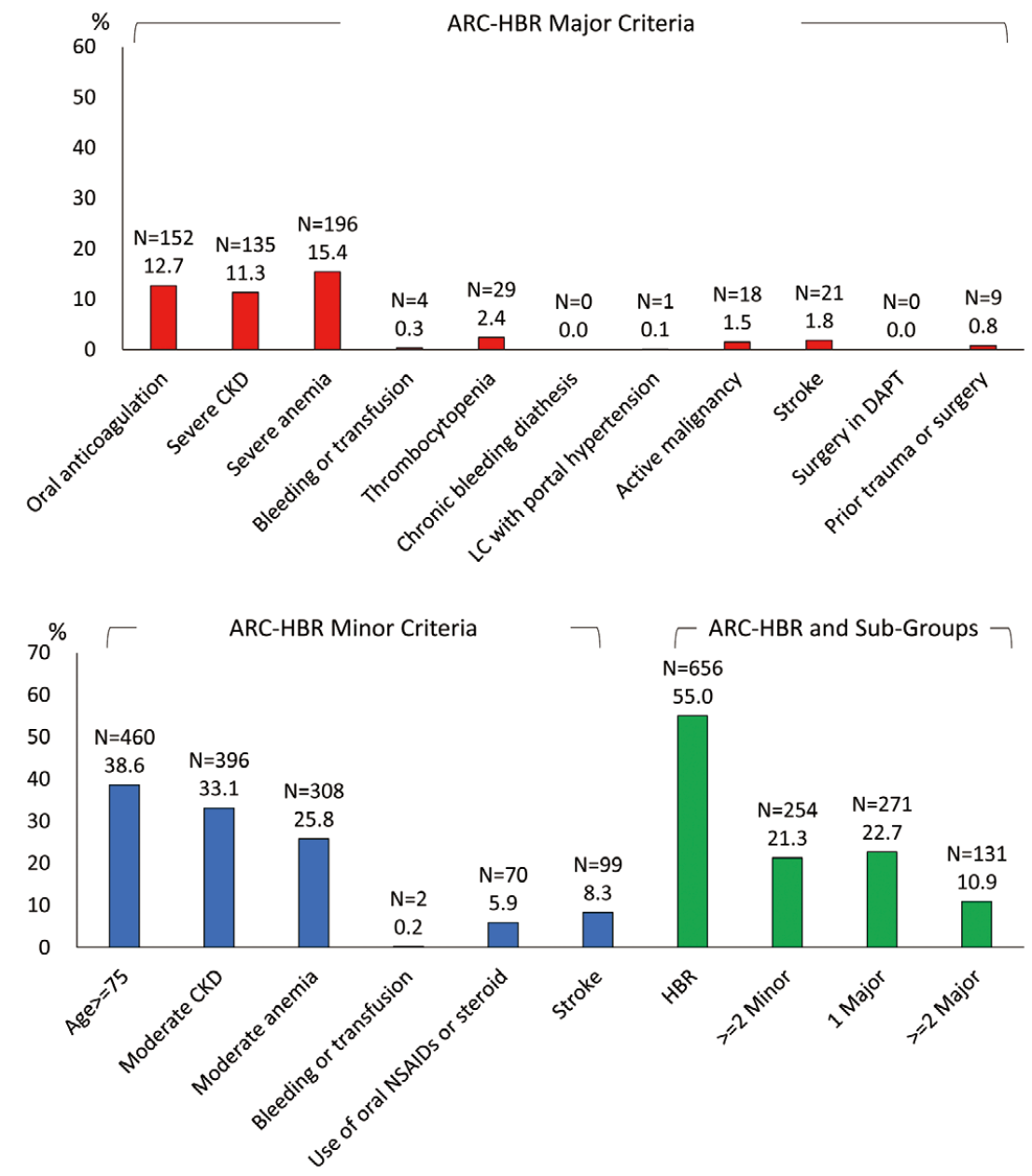

Figure 2. Prevalence of individual criteria of the Academic Research Consortium for High Bleeding Risk definition (ARC-HBR). CKD, chronic kidney disease; DAPT, dual antiplatelet therapy; HBR, high risk bleeding; LC, liver cirrhosis; NSAIDS, nonsteroidal anti-inflammatory drugs.

USA) and R (R Foundation for Statistical Computing, Vienna, Austria).

\section{Results}

\section{Prevalence of HBR}

There were 656 patients (55\%) meeting the ARC-HBR criteria in the present study population. The numbers and prevalence of the individual ARC-HBR criteria are summarized in Figure 2.

\section{Baseline Characteristics}

Baseline patient, lesion, and procedural characteristics of the overall patient population, HBR group, and non-HBR group are indicated in Table 1. Patients in the HBR group were much older and had significantly higher rates of hypertension, diabetes, heart failure, and peripheral artery disease than those in the non-HBR group.

\section{Clinical Outcomes}

Mean follow-up period of the survivors was 2,996 \pm 433 days. The cumulative incidences of clinical events at 8 years are indicated in Table 2 . The cumulative incidences of major bleeding, intracranial bleeding, gastrointestinal bleeding were much higher in the HBR group $(16.2 \%$ vs. $5.7 \%, \mathrm{P}<0.0001 ; 7.2 \%$ vs. $3.0 \%, \mathrm{P}=0.002$ and $7.2 \%$ vs.
$1.8 \%, \mathrm{P}=0.001$, respectively). Bleeding events occurred at a relatively constant rate up to 8 years, and the annual rate of major bleeding in the HBR group was $2.0 \%$ during the 8 years. The rate of DAPT discontinuation was not significantly different during the follow-up period (Supplementary Figure). The cumulative incidence of primary ischemic events was also higher in the HBR group $(12.7 \%$ vs. $8.3 \%, \mathrm{P}=0.001)$.

\section{Prevalence and Influence of Individual Risk Criteria}

Prevalence of all individual risk criteria of the ARC-HBR definition are indicated in Figure 2. In this study population, patients with chronic bleeding diathesis and nondeferrable major surgery on DAPT were not identified. Furthermore, the rate of patients with prior spontaneous bleeding requiring hospitalization or transfusion, liver cirrhosis with portal hypertension, prior trauma or major surgery within 30 days was less than $1 \%$. Among the major criteria, the use of oral anticoagulation, severe chronic kidney disease, severe anemia, and thrombocytopenia were associated with major primary bleeding events during the follow-up (Figure 3, Supplementary Table 2). Among the minor criteria, the cumulative rate of major bleeding in patients with moderate chronic kidney disease was significantly higher than in that of those without. The cumulative incidence of major bleeding tend to be higher as the 


\begin{tabular}{|c|c|c|c|c|}
\hline & Overall & HBR & Non-HBR & $P$ value \\
\hline $\mathrm{n}$ & 1,193 & 656 & 537 & \\
\hline Age, years & $70.1 \pm 11.2$ & $74.9 \pm 9.8$ & $64.3 \pm 9.9$ & $<0.0001$ \\
\hline Male & $861(72.2)$ & $427(65.1)$ & $434(80.8)$ & $<0.0001$ \\
\hline $\mathrm{BMI}, \mathrm{kg} / \mathrm{m}^{2}$ & $24.3 \pm 3.5$ & $23.7 \pm 3.6$ & $25.0 \pm 3.5$ & $<0.0001$ \\
\hline Hypertension & $848(71.1)$ & $495(75.5)$ & $353(65.7)$ & 0.0002 \\
\hline Diabetes mellitus & $467(39.2)$ & $284(43.3)$ & $183(34.1)$ & 0.001 \\
\hline Insulin therapy & $130(10.9)$ & $98(14.9)$ & $32(6.0)$ & $<0.0001$ \\
\hline Dyslipidemia & $745(62.4)$ & $380(57.9)$ & $365(68.0)$ & 0.004 \\
\hline Current smoking & $166(13.9)$ & $52(7.9)$ & $114(21.2)$ & $<0.0001$ \\
\hline eGFR, $\mathrm{mL} / \mathrm{min} / 1.73 \mathrm{~m}^{2}$ & $60.9 \pm 25.7$ & $49.1 \pm 24.7$ & $75.3 \pm 18.7$ & $<0.0001$ \\
\hline $\mathrm{Ccr}, \mathrm{mL} / \mathrm{min}$ & $67.3 \pm 36.9$ & $47.7 \pm 29.2$ & $91.2 \pm 30.8$ & $<0.0001$ \\
\hline Hemodialysis & $68(5.8)$ & $68(10.4)$ & $0(0)$ & $<0.0001$ \\
\hline Severe CKD & $135(11.3)$ & $135(20.6)$ & $0(0)$ & $<0.0001$ \\
\hline Clinical diagnosis & & & & 0.02 \\
\hline STEMI & $208(17.4)$ & $102(15.6)$ & $106(19.7)$ & \\
\hline NSTEMI/UAP & $245(20.5)$ & $124(18.9)$ & $121(22.5)$ & \\
\hline Stable angina & $740(62.0)$ & $430(65.6)$ & $310(57.7)$ & \\
\hline Previous MI & $418(35.0)$ & $245(37.4)$ & $173(32.2)$ & 0.06 \\
\hline Previous stroke & $114(9.7)$ & $95(14.5)$ & $19(3.5)$ & $<0.0001$ \\
\hline Peripheral artery disease & $82(6.9)$ & $61(9.3)$ & $2(3.9)$ & 0.0003 \\
\hline Previous $\mathrm{PCl}$ & $532(44.6)$ & $298(45.4)$ & $234(43.6)$ & 0.52 \\
\hline Previous CABG & $45(3.8)$ & $28(4.3)$ & $17(3.2)$ & 0.32 \\
\hline Multivessel disease & $361(30.3)$ & 209 (31.9) & $152(28.3)$ & 0.18 \\
\hline Heart failure & $128(10.7)$ & $101(15.4)$ & $27(5.0)$ & $<0.0001$ \\
\hline Anemia $(\mathrm{Hb}<11 \mathrm{~g} / \mathrm{dL})$ & $196(16.4)$ & $196(29.9)$ & $0(0)$ & $<0.0001$ \\
\hline Platelet count $<105 / \mathrm{uL}$ & $29(2.4)$ & $29(4.4)$ & $0(0)$ & $<0.0001$ \\
\hline Malignancy & $79(6.6)$ & $18(2.7)$ & $0(0)$ & 0.0001 \\
\hline \multicolumn{5}{|c|}{ Medications at hospital discharge } \\
\hline \multicolumn{5}{|l|}{ Antiplatelet therapy } \\
\hline Thienopyridine & $1,190(99.7)$ & $654(99.7)$ & $536(99.8)$ & 0.98 \\
\hline Aspirin & $1,186(99.4)$ & $652(99.4)$ & $534(99.4)$ & 0.88 \\
\hline Warfarin & $152(12.7)$ & $152(23.2)$ & $0(0)$ & $<0.0001$ \\
\hline Statin & $943(79.5)$ & $471(71.8)$ & $472(87.9)$ & $<0.0001$ \\
\hline$\beta$-blocker & $425(35.6)$ & $249(38.0)$ & $176(32.8)$ & 0.06 \\
\hline ACEI/ARB & $848(71.1)$ & $444(67.7)$ & $404(75.2)$ & 0.004 \\
\hline Calcium-channel blocker & $482(40.4)$ & 275 (41.9) & $207(38.6)$ & 0.24 \\
\hline Proton pump inhibitor & $675(56.6)$ & $387(56.0)$ & $288(53.6)$ & 0.06 \\
\hline $\mathrm{H}_{2}$-blocker & $230(19.3)$ & $111(16.9)$ & $119(22.2)$ & 0.02 \\
\hline \multicolumn{5}{|l|}{ Lesion location } \\
\hline Left main trunk & $94(7.9)$ & $55(8.4)$ & $39(7.3)$ & 0.47 \\
\hline Left anterior descending & $668(56.0)$ & $367(56.0)$ & $301(56.1)$ & 0.97 \\
\hline Left circumflex & $347(29.2)$ & $190(29.0)$ & $157(29.2)$ & 0.92 \\
\hline Right coronary artery & $530(44.4)$ & $297(45.3)$ & $233(43.4)$ & 0.51 \\
\hline Chronic total occlusion & $174(14.6)$ & $90(13.7)$ & $84(15.6)$ & 0.35 \\
\hline In-stent restenosis & $193(16.2)$ & $108(16.5)$ & $85(15.8)$ & 0.77 \\
\hline Bifurcation & $526(44.1)$ & $270(41.2)$ & $256(47.7)$ & 0.02 \\
\hline Ostial lesion & $227(19.0)$ & $124(18.9)$ & $103(19.2)$ & 0.9 \\
\hline $\mathrm{AHA} / \mathrm{ACC} \mathrm{B} 2 / \mathrm{C}$ & $907(76.0)$ & 507 (77.3) & $400(74.5)$ & 0.26 \\
\hline Minimal stent diameter, $\mathrm{mm}$ & $2.75 \pm 0.35$ & $2.75 \pm 0.35$ & $2.75 \pm 0.35$ & 0.80 \\
\hline Total stent number & $2.2 \pm 1.4$ & $2.1 \pm 1.4$ & $2.3 \pm 1.5$ & 0.20 \\
\hline Total stent length, $\mathrm{mm}$ & $47.1 \pm 34.5$ & $45.9 \pm 32.4$ & $48.5 \pm 36.9$ & 0.18 \\
\hline
\end{tabular}

Values are mean \pm SD or $n(\%)$, unless otherwise specified. ACC, American College of Cardiology; AHA, American Heart Association; ACEI, angiotensin-converting enzyme inhibitor; ARB, angiotensin II receptor blocker; BMI, body mass index; CABG, coronary artery bypass graft; Ccr, Creatinine clearance; CKD, chronic kidney disease; CTE, coronary thrombotic event; eGFR, estimated glomerular filtration rate; HBR, high bleeding risk; NSTEMI, non-STelevation myocardial infarction; PCl, percutaneous coronary intervention; STEMI, ST-elevation myocardial infarction; UAP, unstable angina. 
Table 2. Cumulative Incidence of Clinical Outcomes

HBR

$\mathrm{n}$

Major bleeding

Intracranial bleeding

Gastrointestinal bleeding

$\mathrm{MI} / \mathrm{ST} /$ ischemic stroke

$\mathrm{MI}$

Definite/probable ST

Definite ST

Ischemic stroke

All-cause death

Cardiac death

Any TLR

Clinically indicated TLR

\section{No. of patients with events (cumulative 8-year incidence)}

656

70 (16.2)

31 (7.2)

31 (7.2)

$60(12.7)$

$34(7.1)$

$2(0.4)$

$1(0.2)$

$28(6.4)$

$263(42.7)$

$84(16.6)$

$93(16.8)$

59 (11.5)
Non-HBR

No. of patients with events (cumulative 8-year incidence)

537

$27(5.7)$

13 (3.0)

9 (1.8)

31 (8.3)

$17(4.5)$

$3(0.6)$

$3(0.6)$

14 (3.6)

$53(10.4)$

17 (3.6)

$72(14.6)$

$42(9.7)$
HR (95\% Cl)

HBR relative to $\quad P$ value Non-HBR

$2.76(1.80-4.38) \quad<0.0001$

$2.68(1.44-5.29) \quad 0.002$

$1.75(1.25-2.49) \quad 0.001$

$2.01(1.32-3.10) \quad 0.001$

$1.93(1.11-3.47) \quad 0.02$

$0.65(0.09-3.97) \quad 0.64$

$0.32(0.02-2.57) \quad 0.30$

$2.22(1.19-4.34) \quad 0.01$

$5.08(3.82-6.88)<0.0001$

$5.12(3.12-8.92)<0.0001$

$1.21(0.90-1.66) \quad 0.20$

$1.38(0.93-2.06) \quad 0.10$

Data are presented as number of patients with event (cumulative incidence). Event rates estimated using Kaplan-Meier analysis. HR with $95 \%$ $\mathrm{Cl}$ was estimated by univariate Cox proportional hazard model. Cl, confidence interval; HBR, high bleeding risk; HR, hazard ratio; MI, myocardial infarction; ST, stent thrombosis; TLR, target lesion revascularization.

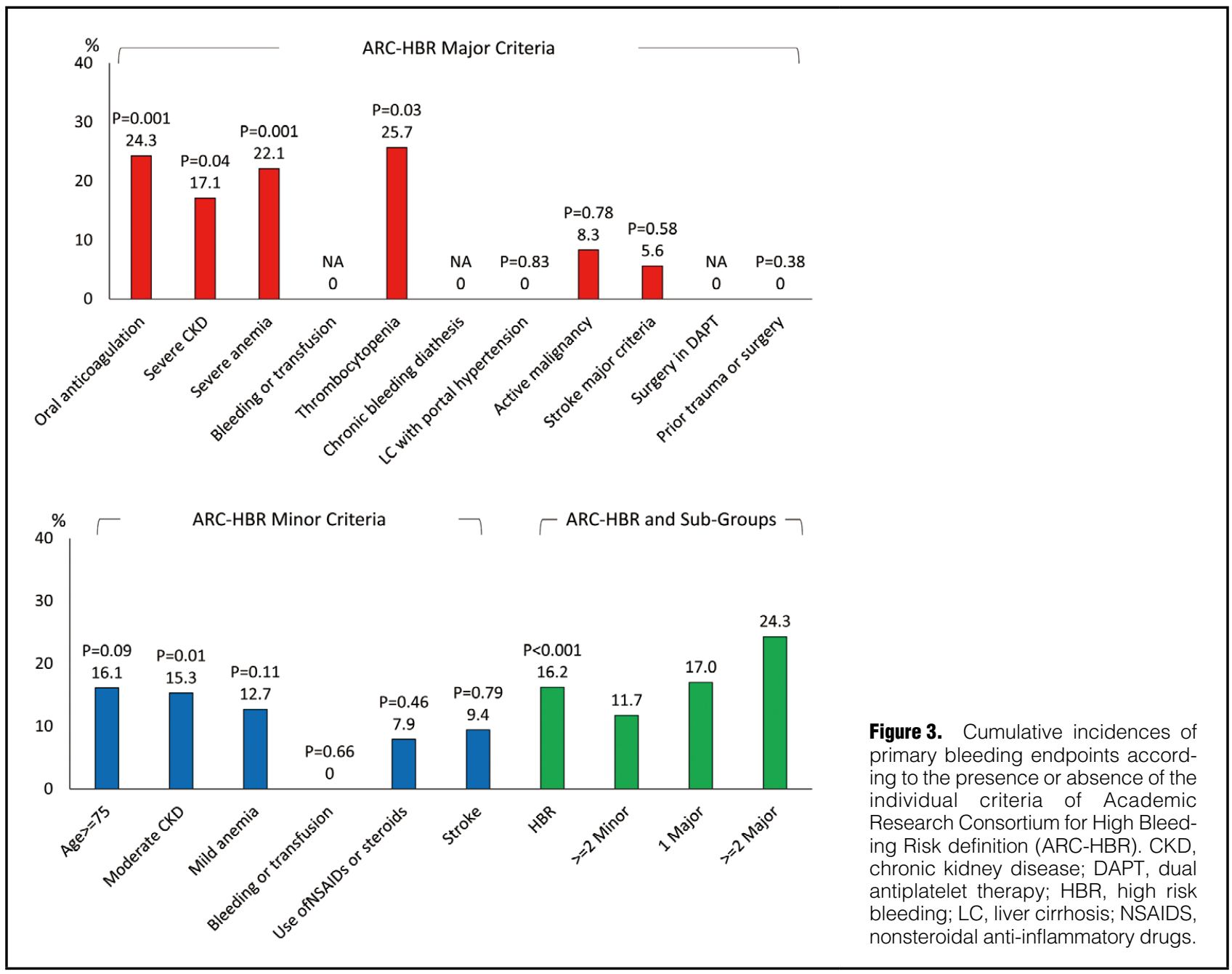



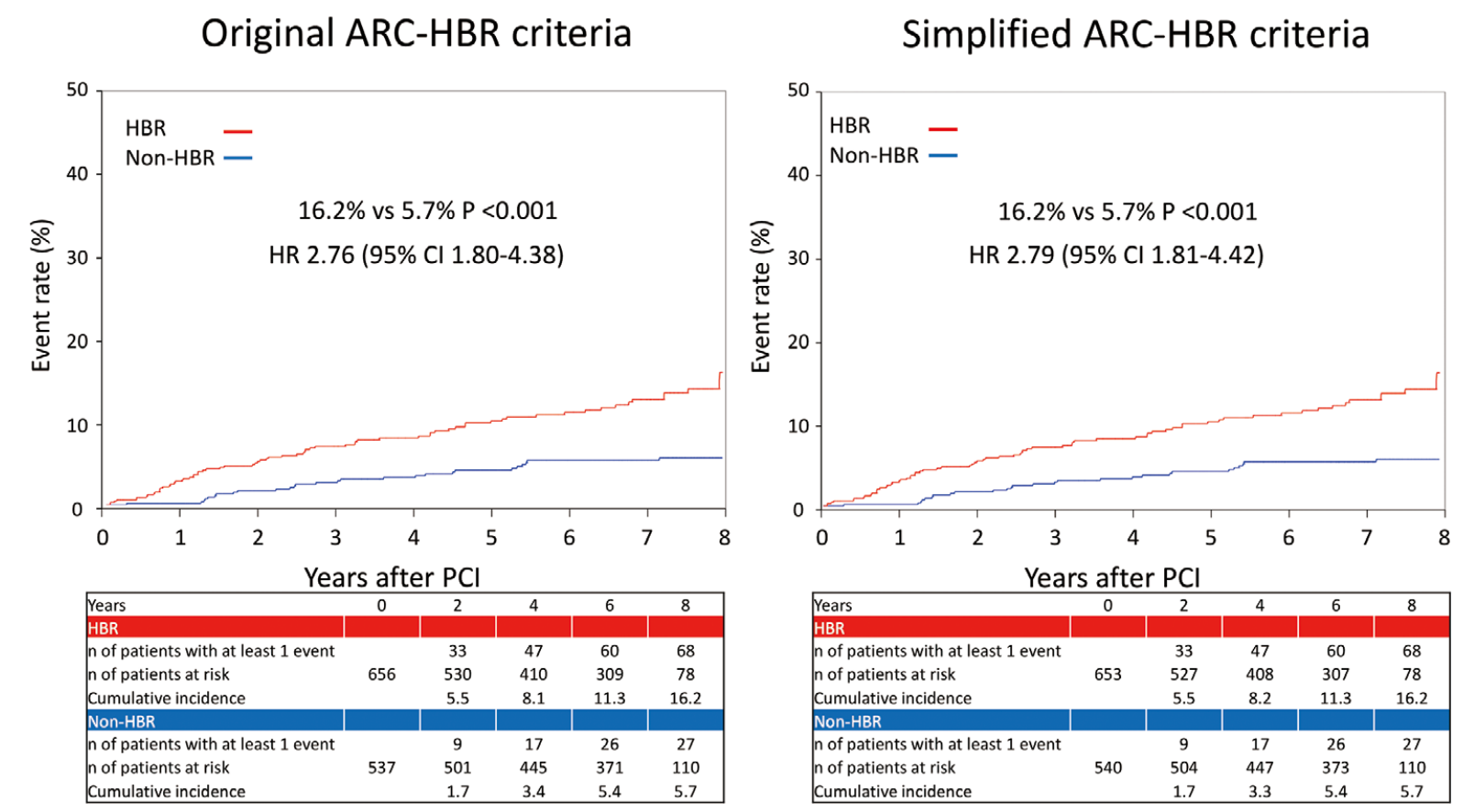

Figure 4. Kaplan-Meier curve of the primary bleeding endpoints according to the original and simplified Academic Research Consortium for High Bleeding Risk definition (ARC-HBR). Cl, confidence interval; HR, hazard ratio; PCl, percutaneous coronary intervention.

number of ARC-HBR major or minor criteria increased ( $\geq 2$ majors: $24.3 \%, 1$ major: $17.0 \%, \geq 2$ minors: $11.7 \%$, non-HBR: $5.7 \%, \mathrm{P}<0.0001)$.

\section{Simplified Definition}

Among all the risk criteria, prevalences of prior bleeding and transfusion defined in both major and minor criteria, chronic bleeding diathesis, liver cirrhosis with portal hypertension, nondeferrable major surgery on DAPT, and prior trauma or surgery within 30 days were less than $1 \%$. We generated a simplified ARC-HBR definition consisting of 11 criteria with frequencies $\geq 1 \% ; 3$ patients in the HBR group under the original definition were reclassified into the non-HBR group under the simplified definition. On the basis of the simplified definition, the cumulative incidence of major bleeding was significantly higher in the HBR group $(16.2 \%$ vs. $5.7 \%$ at 8 years, $\mathrm{P}<0.001$; Figure 4$)$. The area under curve of the original and simplified definitions was comparable (0.598 [95\% CI 055-0.64] and 0.600 [95\% CI $0.55-0.64], \mathrm{P}=0.08$ ). Sensitivity, specificity, positive predictive value, negative predictive value, and accuracy of the original and simplified definitions, respectively, for major bleeding were $73.0 \%, 53.3 \%, 11.1 \%, 95.0 \%$, and $48.8 \%$ and $73.0 \%, 53.1 \%, 11.2 \%, 95.0 \%$ and $49.1 \%$, respectively.

\section{Discussion}

The main findings of this study were as follows. (1) After a retrospective investigation of all the criteria of the ARCHBR definition, $55 \%$ of the patients met the ARC-HBR definition. (2) The frequencies of 6 of 17 criteria were observed infrequently in the real-world setting. (3) The ARC-HBR criteria were associated with long-term bleeding events up to 8 years. (4) The simplified definition generated by excluding low-frequency criteria from the original definition identified patients with long-term bleeding risk as successfully as the original definition.

In the consensus document from the ARC-HBR, HBR was arbitrarily defined as a risk of BARC 3 or 5 bleeding $>4 \%$ at 1 year or that of an intracranial hemorrhage $\geq 1 \%$ at 1 year. ${ }^{18}$ Natsuaki et a ${ }^{13}$ reported the clinical application of selected ARC-HBR criteria, and Sorrentino et al introduced modified ARC-HBR criteria to identify HBR patients because of the limited availability of retrospective data collection. ${ }^{19}$ This study is the first to investigate the prevalence of all of the criteria of the ARC-HBR definition and of the incidence of major bleeding defined by the BARC criteria. In addition, we extended the generality of the ARC-HBR criteria by providing an 8-year incidence of major bleeding in HBR and non-HBR patients. The frequency of HBR was reported to be 33-43\% in all-comer registries in the USA, Switzerland, China, India and Japan if selected ARC-HBR criteria were investigated. .3,19,20 $\mathrm{In}$ this study, in which all ARC-HBR risk criteria were investigated, HBR patients reached $55 \%$, suggesting the frequency of HBR patients might be underestimated in previous reports using selected criteria, and that the rate of HBR patients is not low in daily practice. For such HBR patients, the optimal intensity and duration of DAPT represent a remarkable challenge. ${ }^{21-24}$ Nevertheless, the rate of DAPT discontinuation was relatively lower compared with that recommended in the current guideline and not different between the HBR and non-HBR groups during the long follow-up period. This tendency was in line with that in a large multicenter trial in Japan and it may be explained the fear of ST in the first-generation DES era, which lasted 
until this study period, may have discouraged physicians from discontinuing DAPT. ${ }^{25}$ In addition, patients meeting the ARC-HBR definition might not have been sufficiently taken into account during the study period.

\section{Prevalence of Individual Criteria and Effect on Bleeding Events}

Prior bleeding and transfusion were infrequently observed in this study, probably because elective PCI was avoided in daily practice during this period. The prevalence and effect on bleeding events of active malignancy defined in the ARC-HBR have not yet reported. Although active malignancy was not associated with long-term bleeding events, the cumulative rate of all-cause death was much higher in patients with active malignancy than in those without, which might have affected the rate of long-term bleeding events.

It has been reported that up to $17 \%$ patients undergo an invasive or therapeutic procedure within 1 year after PCI; however, the prevalence of elective major surgery was infrequent in the present study. Either elective major surgery was avoided during the proposed DAPT duration in the guidelines at that time or DAPT duration was shortened in these patients, and urgent major surgery was not performed in the study population.

\section{Simplified Definition}

The original ARC-HBR definition consists of 17 criteria, but some criteria of them were observed infrequently in this study. We proposed a simplified definition, and its discrimination ability was comparable to that of the original definition. This simple definition may be useful for easily identifying HBR patients in daily practice, and may help facilitate subsequent clinical decision making surrounding the treatment strategy and optimal duration of DAPT.

\section{Study Limitations}

First, although we investigated all ARC-HBR criteria by a retrospective method, the prevalence of each criteria may have been potentially underestimated. In addition, the number of patients meeting some criteria was relatively small, especially for the infrequent criteria excluded from the simplified definition. The prevalence and prognostic value of those criteria should be confirmed in large-scale studies. Second, DAPT duration of this study was different from current practice. Third, the bleeding risk in the Japanese population was different from those in USA and European populations. Actually, ethnicity itself has been reported as a risk factor of bleeding events. ${ }^{26,27}$ Therefore, some caution is required to extrapolate the results of this study outside Japan. Finally, our simplified definition was not validated. Further validation studies of this definition are required.

\section{Conclusions}

In our study population, some risk criteria of ARC-HBR definition were observed infrequently. Our simplified definition identified patients with long-term bleeding risk as successfully as the original definition.

\section{Acknowledgments}

We thank Miho Kobayashi, Makiko Kanaike, and Takako Yukiyoshi for their assistance with the manuscript.

\section{Data Availability}

The deidentified participant data that underlie the results reported in this article will be shared upon request to the corresponding author, as Excel or csv files via E-mail, or URL link for individual participant data meta-analysis by investigators whose proposed use of the data has been approved by an independent review committee identified for this purpose, beginning 9 months and ending 36 months after article publication. The study protocol will also be available.

\section{Funding / Disclosures}

None.

\section{IRB Information}

The institutional review board of Kurashiki Central Hospital (Ref. No: 3327).

\section{References}

1. Yeh RW, Kereiakes DJ, Steg PG, Windecker S, Rinaldi MJ, Gershlick AH, et al. Benefits and risks of extended duration dual antiplatelet therapy after PCI in patients with and without acute myocardial infarction. J Am Coll Cardiol 2015; 65: 2211-2221.

2. Sharma A, Agrawal S, Garg A, Vallakati A, Lavie CJ, Helft G. Duration of dual antiplatelet therapy following drug-eluting stent implantation: A systemic review and meta-analysis of randomized controlled trials with longer follow up. Catheter Cardiovasc Interv 2017; 90: 31-37.

3. Mauri L, Kereiakes DJ, Yeh RW, Driscoll-Shempp P, Cutlip DE, Steg PG, et al. Twelve or 30 months of dual antiplatelet therapy after drug-eluting stents. $N$ Engl $J$ Med 2014; 371: $2155-2166$.

4. Mangieri A, Gallo F, Sticchi A, Khokhar AA, Laricchia A, Giannini $F$, et al. Dual antiplatelet therapy in coronary artery disease: From the past to the future prospective. Cardiovasc Interv Ther 2020; 35: 117-129.

5. Kimura K, Kimura T, Ishihara M, Nakagawa Y, Nakao K, Miyauchi K, et al; on behalf of the Japanese Circulation Society Joint Working Group. JCS 2018 guideline on diagnosis and treatment of acute coronary syndrome. Circ $J$ 2019; 83: $1085-1196$.

6. Neumann FJ, Sousa-Uva M, Ahlsson A, Alfonso F, Banning AP, Benedetto U, et al. 2018 ESC/EACTS Guidelines on myocardial revascularization. Eur Heart J 2019; 40: 87-165.

7. Nakamura M, Kimura K, Kimura T, Ishihara M, Otsuka F, Kozuma K, et al. JCS 2020 guideline focused update on antithrombotic therapy in patients with coronary artery disease. Circ J 2020; 84: 831-865.

8. Urban P, Meredith IT, Abizaid A, Pocock SJ, Carrie D, Naber $\mathrm{C}$, et al. Polymer-free drug-coated coronary stents in patients at high bleeding risk. N Engl J Med 2015; 373: 2038-2047.

9. Varenne O, Cook S, Sideris G, Kedev S, Cuisset T, Carrie D, et al. Drug-eluting stents in elderly patients with coronary artery disease (SENIOR): A randomised single-blind trial. Lancet 2018; 391: $41-50$.

10. Natsuaki M, Morimoto T, Yamaji K, Watanabe H, Yoshikawa $\mathrm{Y}$, Shiomi H, et al. Prediction of thrombotic and bleeding events after percutaneous coronary intervention: CREDO-Kyoto thrombotic and bleeding risk scores. J Am Heart Assoc 2018; 7: e008708.

11. Baber U, Mehran R, Giustino G, Cohen DJ, Henry TD, Sartori $\mathrm{S}$, et al. Coronary thrombosis and major bleeding after PCI with drug-eluting stents: Risk scores from PARIS. J Am Coll Cardiol 2016; 67: 2224-2234.

12. Costa F, van Klaveren D, James S, Heg D, Raber L, Feres F, et al. Derivation and validation of the predicting bleeding complications in patients undergoing stent implantation and subsequent dual antiplatelet therapy (PRECISE-DAPT) score: A pooled analysis of individual-patient datasets from clinical trials. Lancet 2017; 389: 1025-1034.

13. Natsuaki M, Morimoto T, Shiomi H, Yamaji K, Watanabe H, Shizuta S, et al. Application of the Academic Research Consortium High Bleeding Risk Criteria in an all-comers registry of percutaneous coronary intervention. Circ Cardiovasc Interv 2019; 12: $\mathrm{e} 008307$.

14. Miura K, Shimada T, Ohya M, Murai R, Amano H, Kubo S, et al. Long-term incidence and details of bleeding events after everolimus-eluting stent implantation: 7-8-year outcomes. Circ J 
2019; 83: 2242-2249.

15. Mehran R, Rao SV, Bhatt DL, Gibson CM, Caixeta A, Eikelboom $\mathrm{J}$, et al. Standardized bleeding definitions for cardiovascular clinical trials: A consensus report from the Bleeding Academic Research Consortium. Circulation 2011; 123: 2736-2747.

16. Cutlip DE, Windecker S, Mehran R, Boam A, Cohen DJ, van Es GA, et al. Clinical end points in coronary stent trials: A case for standardized definitions. Circulation 2007; 115: 2344-2351.

17. Urban P, Mehran R, Colleran R, Angiolillo DJ, Byrne RA, Capodanno $\mathrm{D}$, et al. Defining high bleeding risk in patients undergoing percutaneous coronary intervention: A consensus document from the Academic Research Consortium for High Bleeding Risk. Eur Heart J 2019; 40: 2632-2653.

18. Cutlip DE, Urban P. Validation of standardization: Testing the Academic Research Consortium High Bleeding Risk Criteria. Circ Cardiovasc Interv 2019; 12: e008569.

19. Sorrentino S, Claessen BE, Chandiramani R, Guedeney P, Vogel $\mathrm{B}$, Baber U, et al. Long-term safety and efficacy of durable polymer cobalt-chromium everolimus-eluting stents in patients at high bleeding risk: A patient-level stratified analysis from four post-approval studies. Circulation 2020; 141: 891-901.

20. Ueki Y, Bar S, Losdat S, Otsuka T, Zanchin C, Zanchin T, et al. Validation of Bleeding Risk Criteria (ARC-HBR) in patients undergoing percutaneous coronary intervention and comparison with contemporary bleeding risk scores. EuroIntervention, doi:10.4244/EIJ-D-20-00052.

21. Sorrentino S, Baber U, Claessen BE, Camaj A, Vogel B, Sartori $\mathrm{S}$, et al. Determinants of significant out-of-hospital bleeding in patients undergoing percutaneous coronary intervention. Thromb Haemost 2018; 118: 1997-2005.

22. Capodanno D, Alfonso F, Levine GN, Valgimigli M, Angiolillo DJ. ACC/AHA versus ESC guidelines on dual antiplatelet ther- apy: JACC guideline comparison. J Am Coll Cardiol 2018; 72: 2915-2931.

23. Watanabe H, Domei T, Morimoto T, Natsuaki M, Shiomi H, Toyota $\mathrm{T}$, et al. Very short dual antiplatelet therapy after drugeluting stent implantation in patients with high bleeding risk: Insight from the STOPDAPT-2 trial. Circulation 2019; 140: $1957-1959$.

24. Saito Y, Kobayashi Y, Tanabe K, Ikari Y. Antithrombotic therapy after percutaneous coronary intervention from the Japanese perspective. Cardiovasc Interv Ther 2020; 35: 19-29.

25. Shiomi H, Kozuma K, Morimoto T, Kadota K, Tanabe K, Morino Y, et al. 7-Year outcomes of a randomized trial comparing the first-generation sirolimus-eluting stent versus the newgeneration everolimus-eluting stent: The RESET trial. JACC Cardiovasc Interv 2019; 12: 637-647.

26. Kang J, Park KW, Palmerini T, Stone GW, Lee MS, Colombo A, et al. Racial differences in ischaemia/bleeding risk trade-off during anti-platelet therapy: Individual patient level landmark meta-analysis from seven RCTs. Thromb Haemost 2019; 119: $149-162$.

27. Levine GN, Jeong YH, Goto S, Anderson JL, Huo Y, Mega JL, et al. Expert consensus document: World Heart Federation expert consensus statement on antiplatelet therapy in East Asian patients with ACS or undergoing PCI. Nat Rev Cardiol 2014; 11: $597-606$.

\section{Supplementary Files}

Please find supplementary file(s);

http://dx.doi.org/10.1253/circj.CJ-20-0395 